Márcio Soares

Jefferson P. Piva

\section{Physicians just need to be better trained to provide the best care at the end-of-life}

Received: 31 October 2011

Accepted: 5 November 2011

Published online: 6 January 2012

(C) Copyright jointly held by Springer and ESICM 2011

This editorial refers to the article available at:

doi:10.1007/s00134-011-2400-4.

\section{Soares (®)}

D'Or Institute for Research and Education, Rua Diniz Cordeiro,

30-3 ${ }^{\circ}$ andar, Rio de Janeiro, RJ CEP 22281-100, Brazil

e-mail: marciosoaresms@yahoo.com.br

Tel.: +55-21-25383541

Fax: +55-21-25383541

\section{Soares}

Postgraduate Program, Instituto Nacional de Câncer,

Rio de Janeiro, Brazil

\section{J. P. Piva}

Department of Pediatrics, Hospital de Clínicas de Porto Alegre, School of Medicine, Universidade Federal do Rio Grande Do Sul (UFRGS), Porto Alegre, Brazil

\section{J. P. Piva}

Pediatric Intensive Care Unit, Hospital São Lucas,

School of Medicine, Pontifícia Universidade Católica do Rio Grande Do Sul (PUCRS), Porto Alegre, Brazil

Over the last decades, caring for terminally ill patients, either in the latter phases of progressive chronic diseases or in the setting of refractory organ failures in the course of acute critical illnesses, has become very frequent in intensive care units (ICUs) and such demand is expected to increase substantially in the next decades [1]. Although the end-of-life (EOL) decision-making process and the consequent strategy vary largely depending on several factors such as cultural aspects, religious beliefs, legal burdens, ethical and moral values, medical knowledge regarding terminally ill diseases and palliative care, up to three-quarters of all ICU deaths are preceded by limitations of treatment $[2,3]$. However, the care provided to patients at the EOL and their families needs to be urgently improved. Current information indicates that EOL care in ICUs is frequently inappropriate as a consequence of several factors including poor communication [4], inadequate symptom control [5] and divergence among the ICU team, families and the patients themselves regarding their expectations and values [6]. It is well known that conflicts in the context of EOL are perceived as much more severe and dangerous when compared to other conflicts [6].

Several relevant barriers to improving EOL care at the levels of the patient/family (e.g. inability to participate in EOL discussions, lack of advance directives, unrealistic expectations), the clinician (e.g. both insufficient training in communication and expertise in symptom management, and competing demands on intensivists' time) and the hospital/institution (e.g. inadequacy or absence of local family conferences and lack of palliative care service) were raised by nurse and physician ICU directors in a survey involving 468 ICUs in the United States [7]. In this sense, many interventions have been tested to improve the quality of EOL care with different results. Ethics and palliative care consultations, intensive communication strategies, formal family conferences combined with the bereavement brochure have been demonstrated to improve the quality of EOL care by reducing the length of stay and the use inappropriate ICU resources, preventing conflicts and reducing psychological burden on family members [8-11]. Unfortunately, such interventions are still not widely adopted in ICUs [7]. On the other hand, the benefit of multifaceted quality improvement strategies remains unclear $[12,13]$.

In the current issue of Intensive Care Medicine, Forte et al. [14] present the results of a questionnaire submitted to 105 Brazilian ICU physicians selected from 11 ICUs in 
a university=affiliated hospital evaluating EOL decisions involving a hypothetical severely brain-damaged patient with no family members or advance directives The study has two major findings: (1) physicians who would not apply do-not-resuscitate (DNR) orders less frequently attended EOL classes; and (2) almost half of respondents would not proceed according to what they believed to be most appropriate for the patient (i.e. provide less aggressive treatment), motivated chiefly by legal concerns. As expected, both the interest in and reading about EOL were lower in physicians who would apply "fullcode" status than in those who would decide to withdraw of life-sustaining therapies. Furthermore, the authors also demonstrated that younger physicians and ICU physicians reading at least four articles per year on ethical aspects were more prone to involve family and nurses in the EOL process, as well as make proactive decisions.

Current guidelines recommend that besides a compassionate approach, ICU clinicians should be competent in all aspects of EOL care, including the ability to provide efficient communication, symptom management, and the practical and ethical aspects of different modalities of withdrawing or withholding life-sustaining therapies [15]. Additionally, it has been demonstrated that knowledge of pain control and communication figure among the main skills expected by patients and families of ICU physicians [16]. However, education in medical and nursing schools from many countries (including Brazil) is focused mostly on curative care, and there is little training in palliative medicine, and specific curricular teaching on ethics and communication skills is not available in many schools $[17,18]$. If the ICU staff do not have enough knowledge on EOL there may be disastrous consequences for the patients as well as for the residents and fellows that will be trained with an inadequate and inefficient model [18].

While the legal framework for palliative and EOL care is progressively being reworked in Brazil and other countries, such regulatory changes are usually complex and occur slowly [19]. For all the above-mentioned reasons, the study by Forte et al. will certainly be of help to guide initiatives aiming to improve EOL care as it nicely demonstrates that ethical knowledge positively modifies the EOL decision-making process and provides additional evidence that, like any other procedure or intervention performed in ICUs, specific training in EOL-related topics should be formally incorporated into training programs in critical care.

Acknowledgment Dr. Soares is supported in part by individual research grants from Conselho Nacional de Desenvolvimento Científico e Tecnológico (CNPq).

\section{Conflict of interest None.}

\section{References}

1. Angus DC, Barnato AE, Linde-Zwirble WT, Weissfeld LA, Watson RS, Rickert T, Rubenfeld GD; Robert Wood Johnson Foundation ICU End-Of-Life Peer Group (2004) Use of intensive care at the end of life in the United States: an epidemiologic study. Crit Care Med 32:638-643

2. Prendergast TJ, Claessens MT, Luce JM (1998) A national survey of end-of-life care for critically ill patients. Am J Respir Crit Care Med 158:1163-1167

3. Sprung CL, Cohen SL, Sjokvist P, Baras M, Bulow HH, Hovilehto S, Ledoux D, Lippert A, Maia P, Phelan D, Schobersberger W, Wennberg E, Woodcock T; Ethicus Study Group (2003) End-of-life practices in European intensive care units: the Ethicus Study. JAMA 290:790-797

4. Azoulay E, Chevret S, Leleu G, Pochard F, Barboteu M, Adrie C, Canoui P, Le Gall JR, Schlemmer B (2004) Half the families of intensive care unit patients experience inadequate communication with physicians. Crit Care Med 28:3044-3049
5. Nelson JE, Meier DE, Oei EJ, Nierman DM, Senzel RS, Manfredi PL, Davis SM, Morrison RS (2001) Self-reported symptom experience of critically ill cancer patients receiving intensive care. Crit Care Med 29:277-282

6. Azoulay E, Timsit JF, Sprung CL, Soares M, Rusinová K, Lafabrie A, Abizanda R, Svantesson M, Rubulotta F, Ricou B, Benoit D, Heyland D, Joynt G, Français A, Azeivedo-Maia P, Owczuk R, Benbenishty J, de Vita M, Valentin A, Ksomos A, Cohen S, Kompan L, Ho K, Abroug F, Kaarlola A, Gerlach H, Kyprianou T, Michalsen A, Chevret S, Schlemmer B; Conflicus Study Investigators for the Ethics Section of the European Society of Intensive Care Medicine (2009) Prevalence and factors of intensive care unit conflicts: the Conflicus Study. Am J Respir Crit Care Med 180:853-860

7. Nelson JE, Angus DC, Weissfeld LA, Puntillo KA, Danis M, Deal D, Levy MM, Cook DJ; Critical Care Peer Workgroup of the Promoting Excellence in End-of-Life Care Project (2006) End-of-life care for the critically ill: a national intensive care unit survey. Crit Care Med 34:2547-2553
8. Lilly CM, De Meo DL, Sonna LA, Haley KJ, Massaro AF, Wallace RF, Cody S (2000) An intensive communication intervention for the critically ill. Am J Med 109:469-475

9. Schneiderman LJ, Gilmer T, Teetzel HD, Dugan DO, Blustein J, Cranford R, Briggs KB, Komatsu GI, GoodmanCrews P, Cohn F, Young EW (2003) Effect of ethics consultations on nonbeneficial life-sustaining treatments in the intensive care setting: a randomized controlled trial. JAMA 290:1166-1172

10. Campbell ML, Guzman JA (2003) Impact of a proactive approach to improve end-of-life care in a medical ICU. Chest 123:266-271

11. Lautrette A, Darmon M, Megarbane B, Joly LM, Chevret S, Adrie C, Barnoud D, Bleichner G, Bruel C, Choukroun G, Curtis JR, Fieux F, Galliot R, Garrouste-Orgeas M, Georges H, Goldgran-Toledano D, Jourdain M, Loubert G, Reignier J, Saidi F, Souweine B, Vincent F, Barnes NK, Pochard F, Schlemmer B, Azoulay E (2007) A communication strategy and brochure for relatives of patients dying in the ICU. N Engl J Med 356:469-478 
12. Curtis JR, Nielsen EL, Treece PD, Downey L, Dotolo D, Shannon SE, Back AL, Rubenfeld GD, Engelberg RA (2011) Effect of a qualityimprovement intervention on end-oflife care in the intensive care unit: a randomized trial. Am J Respir Crit Care Med 183:348-355

13. Azoulay E, Siegel MD (2011) Selfefficacy approaches to improving endof-life care for the critically ill: ineffective, insufficient, or inconclusive? Am J Respir Crit Care Med 183:288-290
14. Forte D, Vincent JL, Velasco I, Park M (2011) Association between education in EOL care and variability in EOL practice: a survey of ICU physicians. Intensive Care Med.doi: 10.1007/s00134-011-2400-4

15. Truog RD, Campbell ML, Curtis JR, Haas CE, Luce JM, Rubenfeld GD, Rushton CH, Kaufman DC; American Academy of Critical Care Medicine (2008) Recommendations for end-oflife care in the intensive care unit: a consensus statement by the American College of Critical Care Medicine. Crit Care Med 36:953-963
16. CoBaTrICE Collaboration (2007) The views of patients and relatives of what makes a good intensivist: a European survey. Intensive Care Med 33:1913-1920

17. Soares M, Terzi RG, Piva JP (2007) End-of-life care in Brazil. Intensive Care Med 33:1014-1017

18. Sullivan AM, Lakoma MD, Block SD (2003) The status of medical education in end-of-life care: a national report. J Gen Intern Med 18:685-695

19. Soares M (2011) End of life care in Brazil: the long and winding road. Crit Care 15:110 